\title{
A GRAMÁTICA DE ANCHIETA E A GRAMATICOGRAFIA HUMANÍSTICA RENASCENTISTA
}

\author{
Leonardo Ferreira KALTNER (D) $\boldsymbol{\Delta}$ \\ Universidade Federal Fluminense (UFF) \\ Melyssa Cardozo Silva dos SANTOS (D \\ Universidade Federal Fluminense (UFF)
}

ఠ

OPEN ACCESS

EDITORES

- Miguel Oliveira, Jr. (UFAL)

- René Almeida (UFS)

\section{AVALIADORES}

- Maurício Silva (UNINOVE)

- Neusa Barbosa Bastos (PUC-SP)

SOBRE OS AUTORES

- Leonardo Ferreira Kaltner Conceptualização, Escrita Rascunho Original, Metodologia.

- Melyssa Cardozo Silva dos Santos Escrita - Análise e Edição,

Visualização.

DATAS

- Recebido: 17/02/2021

- Aceito: 12/03/2020

- Publicado: 23/08/2021

COMO CITAR

KALTNER, Leonardo Ferreira; SANTOS, Melyssa Cardozo Silva (2021). A Gramática de Anchieta e a Gramaticografia Humanística Renascentista. Cadernos de Linguística, v. 2, n. 3, e356.

\section{RESUMO}

O presente artigo, derivado de apresentação na conferência Linguistweets, é um relato do projeto de pesquisa Regna Brasillica: o Brasil quinhentista à luz da Historiografia da Linguística, realizado no âmbito do grupo de pesquisas Filologia, línguas clássicas e línguas formadoras da cultura nacional (CNPq/UFF), vinculado ao Programa de Pós-graduação em Estudos de Linguagem da Universidade Federal Fluminense (Posling/UFF). O tema do artigo está relacionado à análise da recepção da corrente de pensamento do humanismo renascentista europeu no Brasil quinhentista, presente na descrição e gramatização das línguas indígenas no contexto missionário da educação humanística da época, sobretudo na gramática de José de Anchieta, a Arte de gramática da língua mais usada na costa do Brasil, publicada em Coimbra no ano de 1595. No artigo são feitas considerações e comentários filológicos para a interpretação do pensamento linguístico anchietano, e considerações acerca da interdisciplinaridade entre a Historiografia da Linguística, a Linguística Missionária e a Linguística Histórica, sobretudo a Tupinologia, campo de estudos que dialoga com a obra anchietana. Analisamos os primeiros capítulos da gramática de Anchieta. 


\section{ABSTRACT}

This article, derived from a presentation at the Linguistweets conference, is an account of the research project Regna Brasillica: o Brasil quinhentista à luz da Historiografia da Linguística. This research project is carried out within the scope of the research group Filologia, línguas clássicas e línguas formadoras da cultura nacional (CNPq/UFF), and this group is linked to the Postgraduate Program in Language Studies at Universidade Federal Fluminense (Posling/UFF). The main theme of the article is related to the analysis of the reception of the current of thought of European Renaissance humanism in 16th century Brazil. This reception is present in the description and grammatization of indigenous languages in the missionary context of humanistic education at that time, especially in José de Anchieta's grammar, Arte de gramática da língua mais usada na costa do Brasil, published in Coimbra in the year 1595. In the article, we make philological considerations and comments for the interpretation of Anchieta's linguistic thought, and make considerations about the interdisciplinarity between Historiography of Linguistics, Missionary Linguistics and Historical Linguistics, especially Tupinology, field of studies that dialogues with the Anchietan work. We analyzed also the first chapters of Anchieta grammar.

\section{PALAVRAS-CHAVE}

Historiografia da Linguística; Gramaticografia; José de Anchieta; Tupinologia; Linguística Missionária.

\section{KEYWORDS}

Historiography of Linguistics; Gramaticography; José de Anchieta; Tupinologia; Missionary Linguistics. 


\section{TUPINOLOGIA E HISTORIOGRAFIA LINGUÍSTICA (HL)}

Os estudos linguísticos sobre as línguas das comunidades indígenas estão no alvorescer da origem do Brasil, desde o período colonial quinhentista, nos círculos intelectuais europeus pioneiros formados nesse contexto, inicialmente de forma empírica, e posteriormente conduzidos pela gramatização de base latina dos humanistas (KALTNER, 2019a, KALTNER et al. 2019b, KALTNER, SILVA, 2019c; KALTNER, 2019d). Ainda que sob viés missionário, com finalidade doutrinária, os intérpretes e humanistas europeus do século XVI tentaram compreender as línguas das comunidades indígenas no Brasil quinhentista, buscando estabelecer contato linguístico, catalogar e descrever a diversidade linguística inicial, o que levou à organização de uma língua para a catequese, como defendemos em estudos anteriores (KALTNER, 2020a, 2020b, 2020c, 2020d, 2020f e KALTNER, SANTOS, 2020e).

Esse processo, que ocorreu ao longo do século XVI, teve seu ápice na publicação da gramática de Anchieta, em 1595: a Arte da língua mais usada na costa do Brasil(ANCHIETA, 1595), pedra angular de uma tradição linguística continuada nos séculos seguintes da colonização e retomada na descrição das línguas indígenas no Brasil dos séculos XIX e XX, já sob uma perspectiva científica e não mais estritamente missionária. A produção intelectual no Brasil quinhentista e seiscentista é relativamente escassa, devido à dependência da produção intelectual de Portugal, em sua formação inicial como colônia:

\footnotetext{
Podem-se citar apenas uns poucos textos linguísticos escritos em terra brasileira ao longo dos três primeiros séculos da colonização, dentre eles a Arte de gramática da linguagem mais usada na costa do Brasil (1990 [1595]), de José de Anchieta (1534-1597), marco inicial da producão linguística brasileira do ponto de vista historiográfico, o Catecismo na língua brasílica (1952 [1618]), consolidado pelo Padre Antônio de Araújo (1566-1632) para uso na doutrinação do gentio, a Arte da língua brasilica (1621), do Padre Luís Figueira (1574-1643), a Arte de gramática da língua brasílica da nação Kiriri (1699) do Padre Luís Vicêncio Mamiani, a Arte da língua de Angola (1697), do jesuíta Pedro Dias (1621-1700) (CAVALIERE, 2012, p. 218).
}

A gramaticografia atual, campo teórico que estuda a história e o desenvolvimento das gramáticas, a partir da gramatização de línguas diversas, fundamentando-se na disciplina de Historiografia da Linguística (HL), é um dos modelos de análise para a gramática anchietana (SWIGGERS, 2013). Para se desenvolver uma análise do pensamento linguístico de Anchieta, a partir de sua gramática, é necessário compreender o seu contexto de produção no Brasil quinhentista, tarefa complexa que requer do historiógrafo da linguística uma abordagem interdisciplinar do tema. Ademais a gramática anchietana é uma das fontes para o estudo da Tupinologia, isto é, o estudo das línguas da família Tupi, pela perspectiva da Linguística Histórica. Torna-se tarefa difícil analisar a gramática anchietana sem abordar a língua dos Tupinambás, também chamada de Tupi antigo, descrita por Anchieta. Passemos a algumas considerações sobre a tupinologia na interpretação da obra de Anchieta. 
Um dos maiores expoentes modernos da tupinologia foi o linguista Aryon Rodrigues (1925-2014), um dos fundadores da Associação Brasileira de Linguística e seu primeiro presidente, que em sua tese de doutoramento, Phonologie der Tupinambá-Sprache (RODRIGUES, 1958), debateu a questão dos estudos sobre as línguas indígenas na época colonial. A Tupinologia é objeto de estudos da Historiografia Linguística $(\mathrm{HL})$ e da Linguística Missionária (LM) no Brasil, pelo fato de que as primeiras manifestações de um pensamento linguístico nesse contexto derivaram de reflexões sobre as línguas indígenas no processo de colonização linguística, sob a política missionária europeia.

A tese de doutoramento de Aryon Rodrigues, defendida em Hamburgo e orientada por Otto von Hessen, cita as principais fontes e corpus para a análise do pensamento linguístico no Brasil do século XVI, sendo a gramática anchietana o principal texto com reflexões metalinguísticas sobre a língua dos Tupinambás, nesse período inicial. A obra foi estudada, no século XIX, por Julius Platzmann, que a verteu para o alemão:

Von dieser ersten Grammatik des Tupinambá brachte Julius Platzmann zwei Ausgaben 1874 und 1876 in Leipzig heraus. Die letztere ist ein Faksimile der Originalausgabe. Weitere Faksimiles sind 1933 in Rio de Janeiro und 1946 in São Paulo erschienen. Platzmann veröffentlichte auch eine deutsche Version: Grammatik der brasilianischen Sprache, mit Zugrundelegung des Anchieta. Leipzig, 1874 (RODRIGUES, 1958, p. 7).

Além da gramática anchietana, fontes que são muito próximas ao século XVI são a gramática de Figueira, o léxico sobre as partes do corpo humano, atribuído a Pero de Castilho e o Vocabulário na língua brasílica (RODRIGUES, 1958). Dignos de nota também são os catecismos e textos doutrinários, as obras literárias, que compõem o corpus de fontes para a Tupinologia que aborda o Brasil quinhentista, cuja análise se desenvolveu no contexto universitário e acadêmico do Brasil do século XX a partir das pesquisas iniciais de Félix Pacheco, sendo a gramática anchietana investigada e interpretada nesse longo percurso, até as edições das obras completas de Anchieta, os Monumenta Anchietana, por Armando Cardoso, de meados até o final do século XX (TUFFANI, 2012). Digno de nota também é o Curso de Tupi Antigo de Lemos Barbosa, no século XX, que também publicou um dicionário da língua, e as obras mais recentes de Navarro, que retomaram as pesquisas de Lemos Barbosa.

O percurso editorial da gramática de Anchieta se inicia em sua redação, o que se deu, provavelmente, entre os anos de 1554 e 1556, na capitania de Piratininga, quando o missionário recém-chegado de Coimbra teve acesso aos intérpretes que já atuavam na região, reduzindo a língua de contato à arte. Essa é o posicionamento de Armando Cardoso,

1 A partir desta primeira edição da gramática da língua dos Tupinambás, Júlio Platzmann imprimiu duas edições, em Leipzig, em 1874 e em 1876. A última é uma versão fac-similada da edição original. Platzmann apresentou também uma tradução alemã da gramática, intitulada: Grammatik der brasilianischen Sprache, mit Zugrundelegung des Anchieta, publicada em Leipzig, em 1874. 
atestado por uma carta de Anchieta (ANCHIETA, 1990). Note-se que o conceito de "reduzir uma língua à arte" é o processo de gramatização renascentista e humanístico, em que as categorias da gramática latina servem de base para a criação de uma escrita vernacular de determinada língua.

A gramática especulativa medieval, que antecedeu ao período humanístico, apenas se vinculava ao uso da língua latina como speculum do mundo. Com os humanistas, outras línguas passaram a ser gramatizadas e essa é a inovação que leva Anchieta, por exemplo, a gramatizar a língua dos Tupinambás do Brasil quinhentista. Anchieta comenta em sua obra que a tal arte gramatical não teria proveito, tendo em vista os outros missionários e intérpretes da região não conhecerem gramática. Podemos interpretar que esse pensamento se deu em virtude de o projeto missionário não estar estabelecido ainda e as instituições educacionais não estarem em funcionamento, com turmas e classes de gramática, na época em que a obra foi redigida, na capitania de São Vicente.

Serafim Leite afirma que o grego não foi ensinado nos colégios jesuíticos (LEITE, 1938), em detrimento da língua indígena, isso em período de expansão do projeto missionário no Brasil, o que ocorre também após a publicação da Ratio Studiorum em 1599, já no contexto da obra de Figueira. Por fim, sobre a recepção da gramática de Anchieta, temos duas notas na gramática de Figueira, uma sobre o uso dificultoso da gramática, na autorização do censor e outra sobre não existir uma gramática da língua brasílica, o que demonstra a recepção da gramática anchietana décadas após sua publicação (FIGUEIRA, 1621).

Ainda que Anchieta não nomeie a língua do Brasil, a que Figueira chamaria de brasílica, o adjetivo nessa forma já aparece em latim na obra literária anchietana, como os Regna Brasillica, uma tradução renascentista de Estado do Brasil. O fato de Anchieta não nomear a língua é o mais polêmico e controverso, o que abre margem para diversas interpretações e especulações, inclusive sobre o rótulo para nomear a língua descrita por Anchieta, a que o exame filológico de Aryon Rodrigues estabeleceu como língua dos Tupinambás, e a tradição como Tupi antigo. É possível que as diversas comunidades indígenas fossem plurilíngues no Brasil quinhentista e essa língua de contato fosse comum entre os diversos grupos de origem Tupi, ou Tupinambá, sobretudo após a gramatização pelos jesuítas, para a catequese. A gramática de Anchieta poderia ter sido escrita para constar no programa de estudos iniciais proposto por Nóbrega, na formação de novos missionários.

Para a análise do pensamento linguístico de Anchieta, tema da HL, é interessante notar que a gramática anchietana se inscrevia em um processo mais amplo de desenvolvimento das reflexões metalinguísticas sobre as línguas faladas pelas comunidades indígenas. $O$ fato de Anchieta não ter nomeado a língua em sua gramática demonstra que havia uma certa preocupação e mesmo dúvida na adoção de uma rotulagem. Anchieta nomeia com etnônimos indígenas os grupamentos limítrofes da 
língua de contato, os Pitiguáres do Paraîba, os Tamôyos do Rio de laneiro, os Tupis de sam Vicente, mas não nomeia a língua (ANCHIETA, 1595).

Anchieta como gramático do período humanístico refletia as tendências de sua época e de sua formação intelectual missionária, inicialmente nas llhas Canárias, em seguida, no Real Colégio das Artes de Coimbra (KALTNER. 2019). Os três primeiros capítulos da gramática de Anchieta, sobre as letras, a ortografia, a pronúncia e o acento, na descrição da língua indígena, demonstram o conhecimento linguístico de fonética e de fonologia da época quinhentista e a aplicação desses pressupostos na transcrição da língua dos Tupinambás. Esse processo de transcrição, que se valia do sistema de escrita latino, é o primeiro passo na gramatização de uma língua pelos humanistas do período renascentista. Praticamente todas as línguas ocidentais modernas foram gramatizadas nesse processo, em que a adoção da escrita vernacular tinha por base a gramática latina, valendo-se de seu sistema de letras e silabário para representar os sons da língua.

Fixar os critérios de transcrição e equivalência fonética do alfabeto latino em determinada língua vernacular definiria como aquele sistema linguístico passaria a ser ensinado institucionalmente e utilizado de forma normatizada, em suma, como passaria a ser representado na escrita. Esse processo ocorre no vernáculo português a partir da obra de gramáticos humanistas como João de Barros, anterior à Anchieta, que em sua gramática de 1540 também delimita o sistema de escrita latino e sua equivalência fonética vernacular na língua portuguesa, no segundo capítulo de sua obra, que é dedicado às letras e ao seu uso (BARROS, 1540). Como a gramática de Anchieta foi escrita em língua portuguesa, mas com alguns metatermos em língua latina, é possível pensarmos que o superstrato de gramatização da língua dos Tupinambás tinha por base uma metalinguagem latino-portuguesa, oriunda da recente tradição humanística, em que Anchieta se inseriu desde o início de sua formação intelectual.

Os três primeiros capítulos da gramática de Anchieta estabelecem os critérios de transcrição para a língua dos Tupinambás, buscando inserir o sistema linguístico indígena na tradição europeia de gramatização de línguas vernaculares, que ocorre no período renascentista. Culturalmente, Anchieta enceta o diálogo entre as culturas indígenas e a cultura ocidental, por uma gramatização de base greco-latina, intermediada pelo vernáculo português, em uma política missionária de tradição judaico-cristã. Esse amálgama cultural era a visão de mundo do humanista quinhentista, sobretudo aquele cuja formação intelectual e missionária era vinculada às culturas ibéricas, como os missionários jesuítas do século XVI, caso de Anchieta, um dos primeiros a integrar a ordem e chegar ao Brasil, na segunda leva oficial de missionários.

O diálogo intercultural que Anchieta trava no desenvolvimento de sua gramática era a busca de se valer da concepção humanística de interação entre povos e culturas. Nesse sentido o buscar compreender e se fazer compreender, a busca pela comunicação 
intercultural era a principal função de sua gramática quinhentista, que inseria as culturas indígenas, sobretudo a de base Tupinambá, nas tradições culturais do mundo ocidental, pelo viés missionário judaico-cristão, mas também pelo pensamento linguístico grecolatino, que serviu de base para a gramatização do vernáculo português.

\section{HUMANISMO RENASCENTISTA E O QUADRO DE GRAMÁTICAS NA ABRANGÊNCIA REFERENCIAL}

José de Anchieta nasceu em 1534, nas llhas Canárias, período de pleno desenvolvimento da corrente de pensamento do humanismo renascentista europeu, com reflexos sob a coroa de Castela, principalmente pela recepção da obra linguística de Nebrija. A educação de Anchieta se inicia no contexto das Canárias, tendo tido provável educação com os dominicanos na ilha, e em casa com familiares, como seu irmão Pedro Nuñez, com quem seguiria para Coimbra em 1548 (VIOTTI, 1980). É possível que Anchieta tenha tido contato com a obra gramatical de Nebrija em sua educação inicial, tendo em vista que chega a Coimbra já como um bom aluno de humanidades. A obra de Nebrija está na abrangência referencial do pensamento linguístico de Anchieta.

Em Coimbra teve como mentor e preceptor Diogo de Teive, humanista que era professor egresso do Colégio de Guiena, dirigido por André de Gouveia, tendo sido um dos bolseiros de D. Manuel I na França (KALTNER, 2019). A obra de Teive teve impacto na produção literária anchietana, principalmente no uso do latim humanístico, pela concepção educacional da época. O quadro de gramáticas latino-portuguesas quinhentistas pode nos revelar a abrangência referencial do pensamento linguístico de Anchieta, a que se acrescem autores notadamente influentes à sua época, como os humanistas Nicolau Clenardo e Despauterius (KEMMLER, 2013).

Após sua vinda ao Brasil, Anchieta teve como principal mentor o jesuíta Manuel da Nóbrega, cuja influência em suas obras é patente. Manuel da Nóbrega buscou sistematizar a educação na colônia nascente, e o projeto literário de Anchieta parece ter estado vinculado a esse projeto propedêutico de um colégio jesuítico inspirado nos cursos de humanidades conimbricenses. O fato de a obra literária de Anchieta tratar de todas as formas da poética clássica e cuidadosamente se valer das quatro principais línguas do projeto colonial português nas Américas é um indício de que sua construção foi motivada.

Com a publicação da gramática de Manuel Àlvares, em 1572, o cenário educacional em Portugal se transforma, principalmente nas instituições administradas pelos jesuítas. Não sabemos ao certo o impacto da obra de Álvares no Brasil quinhentista, talvez uma consulta a fontes indiretas, como os Monumenta Brasiliae, possa elucidar a recepção da obra de Álvares nas classes dos colégios jesuíticos quinhentistas e nos dar indícios sobre 
o seu uso. Após a publicação da Ratio Studiorum, em 1599, que Anchieta não alcança em vida, tendo falecido em 1597, a gramática de Álvares se tornaria hegemônica no ensino de latinidades nas missões e colégios jesuíticos, inclusive no Brasil do século XVII, contexto da gramática de Figueira.

$\mathrm{Na}$ política missionária jesuítica, centrada no diálogo intercultural, mas sob a hegemonia teológica católica, de base cultural judaico-cristã, a gramática anchietana se valia de uma concepção humanística para a universalização da catequese, como supracitado. Esse ideal da época das navegações, vinculado às utopias renascentistas, era um dos motivos da política missionária, que estava patente já no discurso humanístico de fundação do Real Colégio das Artes de Coimbra, em 1548, De liberalium artium studio, em defesa do estudo das artes liberais, proferido por Arnaldo Fabrício (KALTNER, 2019). Esse ideal educacional foi transferido para a colônia ultramarina na América portuguesa pelos primeiros missionários. O padrão educacional da época em Portugal, portanto, influiu produndamente na obra de Anchieta.

O quadro de gramáticas latino-portuguesas editadas em Portugal com essa finalidade de implantar a educação humanística é relativamente diverso, demonstrando uma tendência de passagem da gramática especulativa, estritamente em língua latina, para a gramática humanística, que já registrava o vernáculo em contraste com o latim. Ainda que não tenham sido todas as gramáticas dessa tradição utilizadas por Anchieta, no tempo em que esteve em Coimbra, e mesmo além-mar, esse corpus participa do que a HL convencionou conceituar como clima intelectual (KOERNER, 1996). Sobre a gramaticografia quinhentista em Portugal, Kemmler expõe:

\footnotetext{
Quatro décadas após a impressão da primeira gramática de uma língua vernácula, nomeadamente a Gramática de la lengua Castellana (1492) do espanhol Elio Antonio de Nebrija (1444-1522), a história da linguística portuguesa teve o seu início com a publicação da Grammatica da lingoagem Portuguesa (1536) de Fernão de Oliveira (1507-ca.1581) e da Grammatica da Lingua Portuguesa (1540) de João de Barros (1496-1570). No entanto, é de constatar que à divulgação de gramáticas em vernáculo cabia somente um papel secundário em toda a Europa renascentista, visto que a língua dominante no sistema de ensino (e na maioria da produção metalinguística) era o latim, que con-tinuou a preencher um papel preponderante até meados do século XIX (KEMMLER, 2013, p. 146).
}

\section{O CAPÍTULO SOBRE AS LETRAS: ANCHIETA E JOÃO DE BARROS}

Os três primeiros capítulos da gramática de Anchieta: Das letras, Da ortografia ou pronúncia, Do acento, são dedicados à representação dos sons da língua dos Tupinambás e aos critérios de transcrição pelo sistema de letras e sílabas latinas. Na própria gramática, Anchieta faz menção a isso no término dessa sequência de capítulos: 


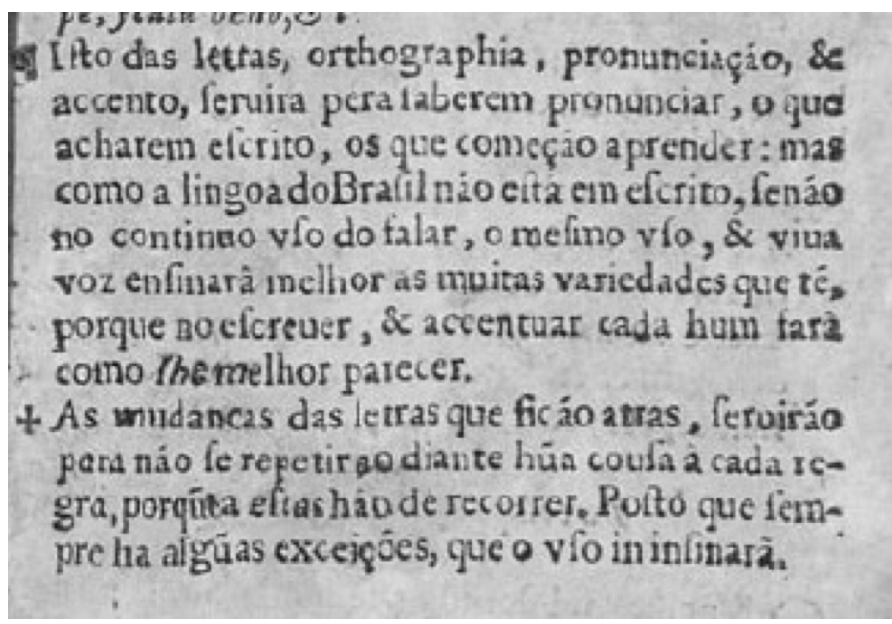

Figura 1. Excerto da gramática anchietana (ANCHIETA, 1595, p. 9f). ${ }^{2}$

O texto, voltado aos que começam aprender a língua por textos escritos, dá uma noção de como falantes de português devem pronunciar a língua indígena no ato da leitura, destacando que essa é uma pronúncia aproximada, e que apenas o uso poderia ensinar a fonética da língua, sobretudo em virtude das "variedades” encontradas. É interessante notar que um humanista do século XVI já possuía em seu repertório gramatical a percepção do conceito de variantes linguísticas, sobretudo no trabalho de transcrição e adaptação de letras latinas na gramatização da língua de contato da América portuguesa.

Anchieta ao descrever o sistema de letras, ou equivalência fonética do uso das letras latinas na representação dos sons da língua dos Tupinambás, em contraste com o vernáculo português, inicialmente, cita os sons que não são representados na língua indígena, isto é, os sons que há no vernáculo português, mas são ausentes na língua dos Tupinambás:

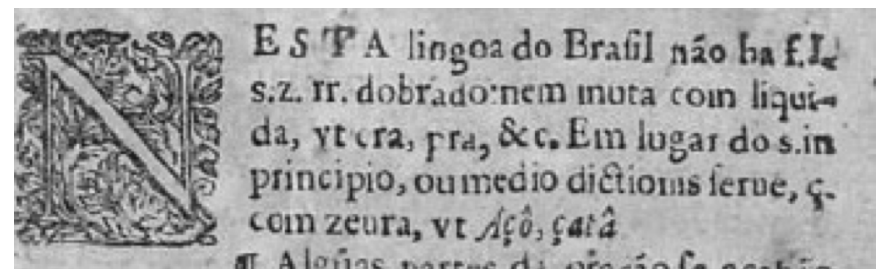

Figura 2. Excerto da gramática anchietana (ANCHIETA, 1595, 1f). ${ }^{3}$

2 Transcrição e adaptação: "Isto das letras, ortografia, pronúncia e acento, servirá para saberem pronunciar o que acharem escrito, os que começam a aprender, mas como a língua do Brasil não está em escrito, senão no contínuo uso do falar, o mesmo uso, e a viva voz ensinará melhor as muitas variedades, que tem, porque no escrever e acentuar, cada um fará como melhor lhe parecer. As mudanças das letras que ficam atrás servirão para não se repetir adiante uma coisa a cada regra, porque estas hão de ser recorrentes. Posto que sempre há algumas exceções, que o uso ensinará".

3 Transcrição e adapatação: "Nesta língua do Brasil não há /f/, /l/,/s/, /z/,/rr/, nem muda com líquida, como /cra/, /pra/ etc. Em lugar do /s/ no início ou no meio da palavra, serve-se do/ç/, com cedilha, como Açô, çatẩ. 
Há dois vocábulos da língua indígena citados na gramática e transcritos por Anchieta, Açô e çatâ. Os vocábulos aparecem sem tradução, e fora de um contexto frasal, ambos foram traduzidos por Julius Platzmann no século XIX para o alemão como ich gehe (eu vou) e es brennt (isto queima), respectivamente (PLATZMANN, 1874, 1876). Já Armando Cardoso, no século XX, os interpretou como "eu vou" e "ele é forte" (ACHIETA, 1990), propondo uma tradução diferente para o segundo vocábulo. A interpretação variável de çatâ se deve justamente à marcação ambígua da vogal por Anchieta e à ausência de tradução na gramática. Se considerarmos que ambas as vogais possuem o mesmo grau de abertura, a leitura de Platzmann é mais plausível. Por fim, Lemos Barbosa interpreta Açô como a-só (assó), "eu fui”, ao tratar como vogal aberta o /ô/ acentuado de Anchieta (LEMOS BARBOSA, 1956, 1967).

O tupinólogo Lemos Barbosa, assim como Navarro posteriormente (NAVARRO, 2021), apresenta atã com o sentido de duro, forte, sendo o /s/ interpretado como o pronome ele, nesse caso, o que leva à interpretação de çatâ, em uma grafia s-atã, de "ele é forte, duro", como Cardoso. Lemos Barbosa apresenta, por outro lado, o termo atá, com o sentido de fogo, que acrescido de /s/ teria o sentido do possessivo dele, nessa concepção, çatâ de Anchieta equivaleria a $s$-atá, isto queima, mais próximo do sentido atribuído por Platzmann, es brennt. Armando Cardoso interpreta a vogal de $A c ̧ \hat{c}$ como uma vogal aberta a-só, eu vou, cuja lição possui concordância com tradução de Platzmann, ich gehe. Navarro apresenta ambas as formas, cujo sentido é tirado do léxico de Lemos Barbosa: "atã (r-s-) - duro: xe ratã - eu sou duro; s-atã - ele é duro; itá-atã - pedra dura / atá (t-r-s-): t-atá - fogo; xe r-atá - meu fogo; s-atá - fogo dele" (NAVARRO, 2021).

A tradução alemã de Julius Platzmann apresenta a seguinte lição do primeiro parágrafo da gramática de Anchieta:

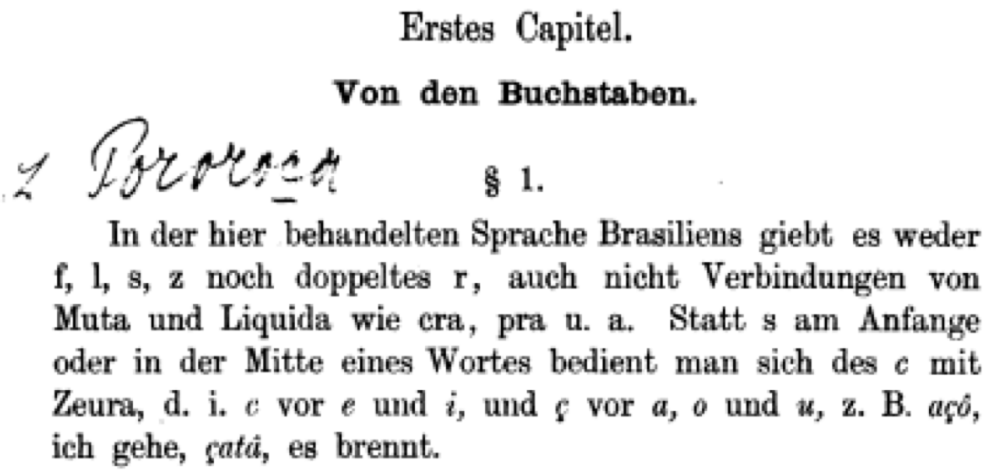

Figura 3. Excerto da tradução de Platzmann (PLATZMANN, 1874, p. 1). ${ }^{4}$ 


\section{A GRAMÁTICA DE ANCHIETA E A DE JOÃO DE BARROS}

O primeiro capítulo da gramática de Anchieta apresenta o rótulo Das Letras (ACHIETA, 1595), título muito próximo do segundo capítulo da gramática vernacular de João de Barros, Da Letera (BARROS, 1540), que está na abrangência referencial de Anchieta e forma o clima de opinião de sua época, na expansão colonial portuguesa. Anchieta não define o conceito de letra em sua gramática, o que talvez não fosse necessário, e mesmo seria redundante, em um contexto em que a obra de João de Barros já poderia estar em uso na catequese e na tentativa de implantação do vernáculo português por missionários no Brasil quinhentista. Este é um cenário plausível, tendo em vista que a política educacional de Nóbrega além de missionária tinha uma base humanística.

Dessa forma, Anchieta apresenta o sistema de letras latinas utilizadas para a transcrição da língua indígena de contato contrastando com o superstrato latinoportuguês, isto é, apenas apresenta e aponta a diferença entre os dois sistemas, iniciando a sua descrição pelas letras e sons ausentes na língua indígena. Fica, portanto, subentendido que os elementos que não são citados são idênticos, entre o vernáculo português e a língua dos Tupinambás, na descrição anchietana. Assim, para compreendermos o sistema de letras e sons, a gramática de João de Barros poderia ser complementar à de Anchieta. Já na gramática de Figueira, posterior à de Anchieta, há uma apresentação mais didática das letras e os sons que representam, na língua brasílica, como o gramático do século XVII rotula a língua de contato inicial.

Vejamos o sistema de escrita proposto por João de Barros, que pode ter sido a base para a descrição anchietana, vinculada ao superstrato latino-português. A definição que João de Barros aplica para letra em sua gramática é compatível com a descrição anchietana, tendo em vista que a publicação da obra gramatical do humanista português se deu em 1540, enquanto Anchieta chega ao Real Colégio das Artes de Coimbra em 1548, vindo ao Brasil em 1553 e inicia apenas em 1554 a redação da gramática, já na Capitania de São Vicente. Para compreendermos os critérios de transcrição de Anchieta da língua dos Tupinambás, os conceitos empregados por João de Barros são fundamentais, tendo em vista que a gramática de Anchieta não repetiria a doutrina de Barros, o que seria redundante, o que nos dá indício também de que poderia ter se apoiado nela.

In den hier behandelten Sprache des Brasiliens giebt es weder f, I, s, z noch doppeltes r, auch nicht Verbindugen von Muta und Liquida wie cra, pra, u.a. Statt s am Anfange oder in der Mitte eines Wortes bedient man sich des c mit Zeura d.i. c vor e und i, und ç vor a o und u, z.B. açó, ich gehe, çatá, es brennt.

Tradução ao português: "Na língua do Brasil, de que tratamos aqui, não há f, l, s, z nem duplo r, nem mesmo combinações de muda e líquida como cra, pra etc. Em vez de s no início ou no meio de uma palavra, o c é usado com zeura, i.e., c antes de e e i, e ç antes de a, o e u, por exemplo açó, eu vou, çatá, queima”. 
O texto a seguir foi transcrito e publicado no portal Tycho-Brahe da Unicamp (BARROS, 1540, 2021), após o excerto transcrito, segue uma tradução vernacular atualizada:

\section{DA LETERA}

Difinçam das leteras e o numero dellas.

LEtera (fegundo os grammàticos) ę amais pequena párte de qualquęr diçam que le póde efcrever: aque os latinos chamáram nóta, e os gręgos carater, per cuia valia e poder formamos as palàuras.

Ea esta formaçam chamã elles primeiros elementos da linguágem: ca bem como do aiuntamento dos quárto elementos fe compõen todalas coulas: affy do aiuntamento das leteras hũas com as outras per órdem natural, le entende cada hum em fua linguágem, pola ualia que pos no leu A, b, c. Donde as leteras veęram ter estas tres coulas, Nome, figura, poder.

Nome, por que á primeira chamam, $\mathrm{A}$, a fegunda, $\mathrm{Be}$, a terçeira, $\mathrm{Ce}$, figura, por que fe efcręvem désta maneira. A, b, c.

Poder, pola valia que cada hũa tem, por que quando achamos ésta letera $\mathrm{A}$, ia fabemos que tem a fua ualia: e per femelhante módo podemos iulgar das outras, que em numero fam vinte \& tres, como as dos latinos de quem âs nós reçebemos.

E dizem amayór párte dos istoriadores, que Nicostrata mádre de Euãdro rey dos Latinos foy inventor destas dezaréte. A, b, c, d, e, f, g, i, l, m, n, o, p, r, l, t, u.

Depois pelo tempo le acreçentáram estas leyes: $h, k, q, x, y, z$. das quáes $h$, tem os Latinos fer efpiraçam e nam letera, e k, que fęrue lómẽte em alguãs dições Gregas como Kyrie eleifon.

Sęruefe tãbem a nórfa linguagem dalgũas leteras á maneira dos Gregos, as quáes nós té óra temos ẽ uóz, mas nam em figura: e lam eftas á, e, ó, de que trataremos no capitolo da Ortografia. E affy temos algũas leteras dobrádas a maneira dos Hebreos: hũas pera o principio de qualquar diçam, outras pera o meo, \& outras pera o fim,

Eas nóflas sam éstas. I, i, y, R, r, S, s, V, u.

Temos mais eftas tres prolações. ch, Ih, nh, as quáes fam próprias da nóßa lingua: e ufamos dellas em foprimento de tres leteras de que nam temos figura.

E affy temos esta letera ç que pareçe fer inventada pera pronũçiaçám Hebráica ou Mourifca: E esta figura- que ę como aręsta a que chamamos til: a qual os latinos tẽ, e fęruenos por eftas leteras $\mathrm{m}$, ve, quando fe põem lobre efta letera q, ou fobre letera vogal.

Alfy q̃ podemos dizer, termos vintatres leteras em poder, \& trinta e quátro em figura.

E onde am de fervir, e quãtos açidentes tẽ particularmẽte trataremos ao diãte, no titolo da Ortografia:

IIto báfte agóra em gęral.

(Da Letra

Definição das letras e o número delas

Letra, segundo os gramáticos, é a menor parte de qualquer palavra que se pode escrever, a qual os latinos chamam de nota e os gregos de caractere, por cujo valor e poder formamos as palavras.

E a esta formação chamam eles os primeiros elementos da linguagem, bem como da junção de quatro elementos se compõem todas as coisas, assim da junção das letras umas com as outras pela ordem natural, se entende cada uma em sua linguagem, pelo valor fonético que pôs no seu A, b, c. De onde as letras vieram a ter estas três categorias: nome, figura e poder (valor fonético). Nome, pelo fato de que à primeira chamam A, à segunda Be, à terceira Ce; figura pelo fato de que se escrevem desta maneira: A, b, c.

Poder pelo valor fonético que cada uma tem, porque quando achamos esta letra A, já sabemos que tem o seu valor, e por semelhante modo podemos julgar sobre as outras, que em número são vinte e três, como as dos latinos, de quem nós as recebemos.

E dizem a maior parte dos historiadores que Nicóstrata, mãe de Evandro, rei dos latinos, foi a inventora destas dezessete letras: A, b, c, d, e, f, g, i, I, m, n, o, p, r, s, t, u.

Depois pelo tempo se acrescentaram estas seis: $h, k, q, x, y, z$, das quais o $h$ tem os latinos ser aspiração, e não letra, e k, que serve somente em algumas palavras gregas, como Kyrie eleison (Senhor, tenha misericórida).

Serve também a nossa linguagem de algumas letras à maneira dos gregos, as quais nós temos ora em voz, mas não em figura, e são estas á, ę, ó, de que trataremos no capítulo da Ortografia. E assim temos algumas letras dobradas, à maneira dos hebreus, umas para o princípio de qualquer palavra, outras para o meio e outras para o fim, e as nossas são estas: I, i, y, R, r, S, s, V, u.

Temos mais estas três prolações: ch, Ih, nh, as quais são próprias da nossa língua, e usamos delas como suprimento de três letras de que não temos figura.

E assim temos esta letra ç, que parece ser inventada pela pronúncia hebraica ou mourisca. E esta figura, que é como uma aresta, a que chamamos til, a qual os latinos têm, e serve-nos por estas letras m, ou quando se põe sobre esta letra q, ou sobre letra vogal.

Assim podemos dizer termos vinte e três letras em poder e trinta e quatro em figura. E onde hão de servir, e quantos acidentes têm particularmente trataremos ao diante, no capítulo da Ortografia

Isto baste agora em geral). 
Do sistema de letras e sons do vernáculo português apresentado por João de Barros, Anchieta afirma que a língua dos Tupinambás não possui as letras f, l, s, z, rr, nem muda com líquida, como cra, pra, e seus respectivos sons, valendo-se do ç para o início e o meio das palavras, a fim de representar o fonema sibilante surdo. O uso do c com cedilha, ç, é feito por Anchieta para reforçar que não há o fonema /z/, a sibilante sonora, na língua dos indígenas Tupinambás, e pode se aproximar a fonema comum em línguas semíticas, como o Hebraico e o Árabe, conforme João de Barros. No primeiro capítulo da gramática ainda, Anchieta apresenta outras diferenças entre o superstrato latino-português e a língua indígena:

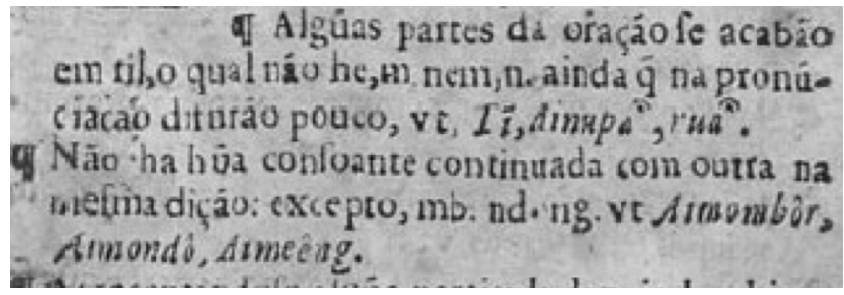

Figura 4. Excerto da gramática anchietana (ANCHIETA, 1595, 1f). ${ }^{5}$

\section{COMPARAÇÃO DA GRAMÁTICA DE ANCHIETA COM A DE FIGUEIRA}

A gramática de Figueira sucedeu à obra de Anchieta, no início do século XVII, buscando atualizar conceitos e a descrição do primeiro período jesuítico. A obra é posterior a grandes avanços no desenvolvimento do pensamento linguístico pelos jesuítas, tendo como fonte a obra de Anchieta, como atesta a licença de publicação. A época em que foi escrita é posterior à publicação da gramática de Manuel Álvares e foi publicada após a promulgação da Ratio Studiorum de 1599, podendo colher de um sistema educacional e colonial mais estável do que o da época de Anchieta.

Dessa forma, a gramática de Figueira dá a impressão ao leitor de ter sido melhor organizada do que a gramática de Anchieta, já no contexto dos colégios jesuíticos coloniais e com uma maior institucionalização da educação humanística na colônia. Essa impressão se dá porque Figueira já participava de uma época derivada dos esforços iniciais dos primeiros missionários quinhentistas. A obra de Anchieta apresenta toda a natureza de

5 Transcrição e tradução: "Algumas partes da oração se acabam em til, o qual não é m, nem n, ainda que na pronúncia difiram pouco, como $\pi$, Ainupã, ruã. Não há uma consoante continuada com outra na mesma palavra, exceto mb, nd, ng, como Aimombôr, Aimondô, Aimeêng". 
dificuldades técnicas e intelectuais para a gramatização de uma língua no contexto quinhentista. A época de Anchieta era um momento histórico de grandes indefinições, mesmo no projeto colonial e no primeiro encontro com as comunidades indígenas.

Na gramática de Figueira, o sistema de escrita da língua brasílica, como chama a língua dos Tupinambás, parece ser organizado de maneira mais simples e direta, apresentando de forma didática o sistema de escrita latino-português para a língua indígena. Basicamente, as informações são as mesmas da gramática anchietana, porém, com outra descrição:

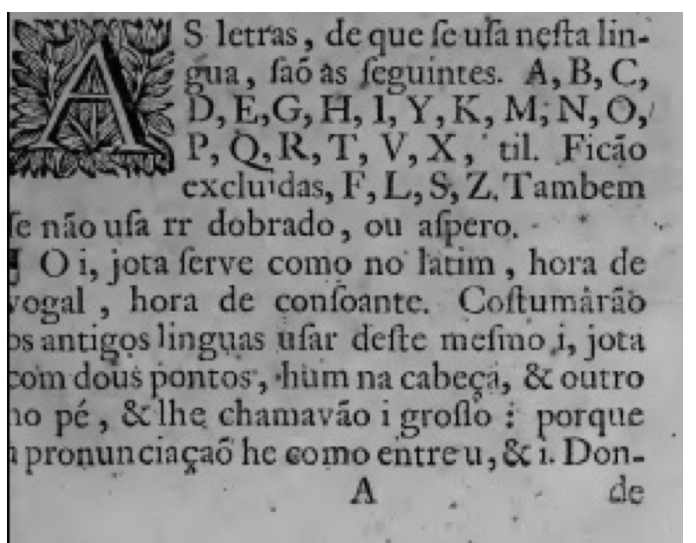

Figura 5. Excerto da gramática de Figueira (FIGUEIRA, 1621, p. 1). ${ }^{6}$

\section{CONSIDERAÇÕES FINAIS}

A partir das relações entre o Brasil e a Europa, no século XVI, período inicial da colonização, nota-se um desenvolvimento pioneiro do pensamento linguístico no contexto intercultural da formação do Brasil, ainda como colônia ultramarina portuguesa. A intelectualidade missionária europeia formou nesse contexto o círculo intelectual incipiente do Brasil, cuja tarefa linguística foi estabelecer uma língua para a catequese e para o estabelecimento das primeiras alianças entre europeus e indígenas na ocupação territorial. O trabalho empírico de intérpretes ficou registrado na documentação da época, assim como o processo de gramatização da língua de contato pelos humanistas, como Anchieta, ficou registrado em documentos diversos, sendo o mais notável, no contexto quinhentista, a Arte de gramática da língua mais usada na costa do Brasil, de 1595, tipografada em Coimbra.

6 Transcrição adaptada: "As letras de que usa nesta língua são as seguintes: A, B, C, D, E, F, G, H, I, Y, K, M, N, O, P, $\mathrm{Q}, \mathrm{R}, \mathrm{T}, \mathrm{V}, \mathrm{X}$, til. Ficam excluídas F, L, S, Z. Também não se usa rr dobrado, ou áspero. O i jota serve como no latim, hora de vogal, hora de consoante. Costumaram os antigos línguas usar deste mesmo i jota com dois pontos, um na cabeça e outro no pé, e como lhe chamavam i grosso, porque a pronúncia é como entre u e i." 
A diversidade linguística e multicultural no Brasil do século XVI perduraria por todo o período colonial, concomitante à implantação do vernáculo português, como superstrato e língua do colonizador. Refletir sobre a história do pensamento linguístico no Brasil, seu desenvolvimento, continuidades e descontinuidades, é tarefa da disciplina de HL. Nesse aspecto, convém analisar a produção intelectual do Brasil quinhentista, ainda que escassa, mas suficiente para se estabelecer uma percepção do desenvolvimento da colônia. Procuramos demonstrar que a gramática anchietana está vinculada a um contexto mais amplo do que a América portuguesa, na recepção da educação humanística renascentista, dentro da política missionária jesuítica que se instiviv em 1549.

Além da gramática de Anchieta, outras obras como um catecismo na língua brasílica, um vocabulário, textos teatrais e poéticos diversos apresentam aos pesquisadores atuais um corpus sobre o Brasil do século XVI inestimável na busca pela constituição de uma narrativa sobre a história do pensamento linguístico nesse contexto. O presente artigo apresenta resultados parciais do projeto de pesquisa Regna Brasillica: o Brasil quinhentista à luz da Historiografia Linguística, desenvolvido na Universidade Federal Fluminense, no âmbito de seu Programa de Pós-graduação em Estudos de Linguagem e é resultado parcial de uma pesquisa que tem por objetivo descrever a recepção da corrente de pensamento do humanismo renascentista europeu, no Brasil quinhentista.

\section{REFERÊNCIAS}

ANCHIETA, José de. Arte de gramática da língua mais usada na costa do Brasil. Coimbra: António de Mariz, 1595.

ANCHIETA, José de. Artes de gramáica da língua mais usada na costa do Brasil. Introdução, tradução e notas de Armando Cardoso. São Paulo: Loyola, 1990.

BARROS, João de. Gramática da língua portuguesa. Lisboa: Lodovicum Rotorigum, 1540.

BARROS, João de. Gramática da língua portuguesa - transcrição. Disponível em:

http://www.tycho.iel.unicamp.br/corpus/cgi-bin/getversion_edictor.pl. Acesso em 15 fev. 2021.

CAVALIERE, Ricardo Stavola. Gramaticografia da língua portuguesa no Brasil: tradição e inovação. Limite, n. 6, p. 217-236, 2012.

FIGUEIRA, Luis. Arte da lingua brasilica. Lisboa: Manuel da Silva, 1621.

KALTNER, Leonardo Ferreira. As ideias linguísticas no discurso De Liberalium Artium Studiis (1548). Confluência, Rio de Janeiro, n. 56, p.197 - 217, 2019a.

KALTNER, Leonardo Ferreira; SANTOS, M. C. S.; TEIXEIRA, V. L. Gaspar da Índia: o língua e o Brasil quinhentista. Confluência, v.57, p. 9-35, 2019b.

KALTNER, Leonardo Ferreira.; SILVA, S. C. S. Gramáticas e gramaticografia: uma análise pela Historiografia Linguística. Revista Philologus, Rio de Janeiro, ano 25, n. 75, v. 2 p.1564 - 1572, set./dez. 2019c.

KALTNER, Leonardo Ferreira. O Brasil quinhentista e a Historiografia Linguística: interfaces. Cadernos do CNLF (Cifefil), n. 23, p.424-439, 2019d. 
KALTNER, Leonardo Ferreira. Monumenta Anchietana à luz da Historiografia Linguística: o trabalho filológico de Pe. Armando Cardoso, SJ (1906-2002). Cadernos de Linguística da Abralin, ano 1, n.1, p.01-15, 2020a.

KALTNER, Leonardo Ferreira. O pensamento linguístico de Anchieta e de Carl von Martius: estudos historiográficos. Ponta Grossa: Atena Editora, 2020b.

KALTNER, Leonardo Ferreira. Por uma edição crítica da gramática de Anchieta (1595). Revista Philologus, Rio de Janeiro, ano 26, n. 76, v. 2., p.717 - 731, set./dez. 2020c.

KALTNER, Leonardo Ferreira. Regna Brasillica: contextualização da Arte de gramática da língua mais usada na costa do Brasil (1595). Revista da Abralin, n.19, p.1 - 25, 2020 d.

KALTNER, Leonardo Ferreira; SANTOS, M. C. S. Schola Aquitanica e a gramática de Despauterius: intertextualidades. Revista Philologus, Rio de Janeiro, n. 76, v. 2, p.750-759, 2020e.

KALTNER, Leonardo Ferreira. The Grammar Corpus in the Horizon of Retrospection of S. José de Anchieta, SJ (1534-1597). Global Journal of Human-social Science: G Linguistics \& Education, n. 20, p.37-44, 2020f.

KEMMLER, Rolf. Para uma melhor compreensão da história da gramática em Portugal: a gramaticografia portuguesa à luz da gramaticografia latinoportuguesa nos séculos XV a XIX. Veredas: Revista da Associação Internacional de Lusitanistas, n. 19, p. 145-176, 1 jun. 2013.

KOERNER, Konrad. Purpose and scope oh Historiographia Linguistica. Historiographia Linguistica, v. 1, n. 1, p. $1-10,1974$.

KOERNER, Konrad. Questões que persistem em Historiografia da Linguística. Revista da Anpoll, n. 2, p. 45-70, 1996.

LEITE, Serafim. História da Companhia de Jesus no Brasil. Lisboa: Livraria Portugália, 1938.

LEmos BARBosA, A. Curso de Tupi Antigo; Gramática, Exercícios, Textos. Rio de Janeiro: São José, 1956.

Lemos BARBosA, A. Pequeno Vocabulário Tupi-Português. Rio de Janeiro: São José, 1967

NAVARRO, Eduardo. Vocabulário Tupi-Português do curso elementar de Tupi Antigo. Disponível em: http://tupi.fflch.usp.br/vocabulariotupiportugues. Acesso em 15 fev. 2021.

PLATZMANN, Julius. Arte de grammatica da lingoa mais usada na costa do Brasil, feita pelo Pe. Joseph de Anchieta. Edição fac-símile. Leipzig: Teubner, 1876

PLATZMANN, Julius. Grammatik der Brasilianischen Sprache mit zugrundelung des Anchieta. Leipzig: Teubner, 1874.

RODRIGUES, Aryon Dall'Igna. Phonologie der Tupinambá-Sprache. 1958. Tese (Douto-rado em Linguística) Faculdade de Filosofia, Universidade de Hamburgo, 1958.

SWIGGERS, P. A historiografia da linguística: objeto, objetivos, organização. Confluência, n. 44-45, p. 39-59, 2013.

TUFFANI, Eduardo. Uma tese de Tupi antigo I. Revista Philologus, n. 52, p. 134-162, 2012.

VIOTTI, Hélio. Anchieta, o Apóstolo do Brasil. São Paulo: Loyola, 1980. 